\title{
Survival of patients with urinary bladder cancer in Jordan, 2005-2014
}

Nour Abdo, ${ }^{1}$ Majd Alsoukhni, ${ }^{1}$ Anwar Batieha ${ }^{1}$ and Kamal Arqoub ${ }^{2}$

${ }^{1}$ Public Health and Community Medicine Department, Faculty of Medicine, Jordan University of Science and Technology, Irbid, Jordan. ${ }^{2}$ Department of Noncommunicable Diseases, Ministry of Health, Amman, Jordan (Correspondence to: Nour Abdo: nmabdo@just.edu.jo).

\begin{abstract}
Background: Urinary bladder cancer is the fourth most common cancer in Jordan. No research on survival from bladder cancer at the national level has been conducted before.

Aims: This study aimed to estimate the probability of survival in patients with bladder cancer in Jordan and identify factors associated with survival.

Methods: Data were obtained from the database of the Jordan cancer registry. All cases of urinary bladder cancer in Jordanians registered during 2005-2014 were included in the study $(n=2139)$. Data collected for each case included: age, sex, date of diagnosis, and stage and grade at diagnosis. Actuarial life table survival analysis was used to determine the overall survival probabilities. Cox proportional hazard regression was used to identify independent factors associated with survival.
\end{abstract}

Results: The overall 1-, 3-, 5- and 10-year survival probabilities for urinary bladder cancer were $85 \%$, 73\%, 69\% and 59\%, respectively (standard error $=0.01$ for each). No significant difference in survival probabilities was found between males and females $(P=0.642)$. The overall survival probabilities decreased significantly as age at diagnosis increased $(P<0.005)$. Better survival was observed in patients with early stage and well differentiated tumours at diagnosis.

Conclusions: The survival of patients with bladder cancer in Jordan is comparable to that reported from developed countries. A high percentage of data was missing and the reporting of some variables was inconsistent. To improve the quality of cancer data, regular training is needed for hospital focal points on recording complete data.

Key words: urinary bladder cancer, survival analysis, life tables, Jordan

Citation: Abdo N; Alsoukhni M; Batieha A; Arqoub K. Survival of patients with urinary bladder cancer in Jordan, 2005-2014. East Mediterr Health J. 2021;27(7):648-655. https://doi.org/10.26719/2021.27.7.648

Received: 26/04/20; accepted: 11/10/20

Copyright $@$ World Health Organization (WHO) 2021. Open Access. Some rights reserved. This work is available under the CC BY-NC-SA 3.0 IGO license (https://creativecommons.org/licenses/by-nc-sa/3.0/igo).

\section{Introduction}

Urinary bladder cancer is a form of cancer primarily arising in the tissues of the urinary bladder. It is the most common malignancy of the urinary system. There are three main types of bladder cancer: transitional cell carcinoma, squamous cell carcinoma and adenocarcinoma (1). Urothelial (transitional cell) carcinoma is the most common histological type of bladder cancer, accounting for almost $90 \%$ of all cases. Squamous cell carcinoma accounts for about $4 \%$ of cases of bladder cancer, adenocarcinoma for about $2 \%$ and all other types for about $4 \%$ of cases (2).

According to the global cancer statistics, bladder cancer is the 1oth most common cancer in the world, with an estimated 549393 new cases and 7.2/100 100 population crude death rate in $2018(3,4)$. About $60 \%$ of all bladder cancer cases and $50 \%$ of bladder cancer deaths occur in the less developed regions of the world (5). Greece is reported to have the highest rates of bladder cancer among men with an age standardized rate of 40.4 cases per 100000 , while Lebanon has the highest rate among women with 9.4 cases per 100000 in 2018 (6). According to the National Cancer Institute in the United States of America (USA), urinary bladder cancer is the sixth most common cancer in the country, accounting for $4.7 \%$ of new cases of cancer and $2.8 \%$ of all cancer deaths in 2017 (7). The 5-year, 10-year and 15-year survival rates were $77.3 \%, 70.0 \%$ and $65.0 \%$, respectively (8). Survival rates varies significantly among age groups. The overall 5-year survival decreased significantly from $90.8 \%$ in patients younger than 50 years to $81.3 \%$ in patients older than 50 years (9). In Sweden, the 5-year relative survival rate for 31266 patients (74\% men, 26\% women) with urinary bladder cancer diagnosed from 1997 to 2011 was $72 \%$ (10). In the Islamic Republic of Iran, the 1-, 3-, 5- and 10-year relative survival rates for 514 patients from 2001 to 2009 were $89.9 \%, 71.3 \%, 57.5 \%$, and $24.6 \%$, respectively. Significant differences in survival rates among age groups and treatment types were also found. Older patients had lower survival rates. Patients who received chemotherapy or radiotherapy alone had lower survival rates than those who received combination therapy (radiotherapy and chemotherapy) (11).

In Jordan, urinary bladder cancer is the fourth most common cancer with 537 new cases reported in 2018, accounting for $4.9 \%$ of all cancer cases diagnosed (3). In 2013, the annual report of the Jordan cancer registry shows that $4.1 \%$ of cancer deaths were due to bladder 
cancer (4). However, no research on survival from urinary bladder cancer at the national level has been conducted before. Our study is the first to assess the survival of patients with urinary bladder cancer in Jordan. The main objectives of this study were to estimate the probability of survival in patients with bladder cancer in Jordan and identify factors associated with survival.

\section{Methods}

\section{Study design and population}

This was a survival analysis of patients with bladder cancer. All Jordanians with urinary bladder cancer registered in the Jordan cancer registry between 2005 and 2014 were included in this study. The Jordan Cancer Registry has a CanReg format. The registry has focal points in each hospital assigned to obtain all needed data for any case of cancer and report it to the cancer registry. All diagnosed urinary bladder cancer cases are notified and registered in the Jordan cancer registry.

\section{Data collection}

The data collected included: personal information (age, sex and national identification number), demographic information (telephone number, address and nationality) and tumour information (stage, grade, date of diagnosis, primary site and histology). All data from this study were obtained from the national cancer registry.

The date of the last contact for all cases was 30 October 2017 which is when our data were obtained from the Jordan cancer registry database. The vital status (whether the case had died or survived) and the date of death were obtained from the civil registration department, which is updated yearly using the national identification number for all cases.

The follow-up period was calculated by subtracting the date of diagnosis from the date of death for the cases that died, and subtracting the date of diagnosis from the 30 October 2017 (the last updated date for vital status in Jordan cancer registry) for those who had survived until the last date of check-up. The end point of the follow-up was death. We assumed that bladder cancer was the cause of death for the cases that died in the study population. However, there might be other underlying causes of death apart from cancer because the cancer registry does not have full access to data on specific cause of death.

\section{Data analysis}

We used SPSS, version 20 to analyse the data. We used actuarial life table survival analysis to determine overall survival probabilities over time. We also computed separate life tables according to relevant variables such as stage and grade of cancer at diagnosis, and age and sex of the case. We used Cox proportional hazard regression analysis to identify independent factors related to survival. A $P$-value $\leq 0.05$ was considered statistically significant. We used RGui, 2.15.1 to plot the overall survival with confidence intervals in Figure 1. We used GraphPad
Prism 5 to plot survival by sex, age, and cancer grade and stage in Figures 2 and 3.

\section{Ethical considerations}

Ethical approval was obtained from the Institutional Review Board in Jordan University of Science and Technology (IRB \# 6/111/2017), the Jordanian Ministry of Health and the deanship of research committee (research no. 20170382).

This research was based on a secondary analysis of national data from the cancer registry. We neither obtained nor used individual names and identifiers in our analysis. The need for informed consent was therefore waived by the review bodies mentioned above.

\section{Results}

\section{Characteristics of the cases}

A total of 2139 patients diagnosed with urinary bladder cancer were registered in the Jordan cancer registry during the period 2005-2014. Men accounted for $87.8 \%$ of the cases. More than $60 \%$ of the patients were older than 60 years at diagnosis in both sexes. For all patients (males and females combined), the median age at diagnosis was 63 years, inter-quartile range (IQR): 52-74. The demographic and clinical characteristics according to sex are shown in Table 1. Most patients (57.7\%) had localized tumours. The greatest proportion for both men and women were poorly differentiated tumours, $38.4 \%$ and $30.7 \%$, respectively. Of all patients diagnosed between 2005 and 2014, 35.4\% had died by the end of 2017 .

\section{Overall survival}

We included 2083 patients in the survival analysis: 56 patients were excluded because of missing data on follow-up time. The patients were followed to the last date of observation: 30 October 2017 if the patient was alive and the date of death if the patient had died. Follow-up time ranged from a few months to 12.8 years with a median of 5 (IQR: $2.3-8.2$ ) years. The overall 1-, 3-, 5- and 10-year survival probabilities for urinary bladder cancer were $85 \%, 73 \%, 69 \%$ and $59 \%$, respectively with standard error of 0.01 for each (Table 2 and Figure 1). Just over half $(55 \%)$ of the patients were alive at the end of the follow-up period.

\section{Survival by sex and age group}

The difference in survival probability between males and females was insignificant $(P=0.642)$ (Figure 2A). The overall survival probabilities decreased significantly as the age increased (Figure 2B). Patients younger than 50 years had significantly higher overall survival probabilities compared with the older age groups: the 1-, 3-, 5- and 10-year survival probabilities decreased significantly from $93 \%, 87 \%, 85 \%$ and $80 \%$ for those aged $<50$ years to $77 \%, 61 \%, 53 \%$ and $43 \%$, respectively, for those aged $\geq 70$ years $(P<0.001)$.

Survival probability decreased in females with increasing age, but the difference was not statistically 


\begin{tabular}{|c|c|c|c|}
\hline \multirow[t]{2}{*}{ Characteristic } & Females $(n=261)$ & Males $(n=1878)$ & Total $(n=2139)$ \\
\hline & No. (\%) & No. (\%) & No. (\%) \\
\hline \multicolumn{4}{|l|}{ Age (years) } \\
\hline $19-49$ & $43(16.8)$ & $316(17.0)$ & $359(16.9)$ \\
\hline $50-59$ & $39(15.2)$ & $373(20.0)$ & $412(19.5)$ \\
\hline $60-69$ & $70(27.3)$ & $558(30.0)$ & $628(29.7)$ \\
\hline$\geq 70$ & $104(40.6)$ & $615(33.0)$ & $719(33.9)$ \\
\hline Mean (SD) & $64(24-94)$ & $63(19-94)$ & $63(13.2)$ \\
\hline Median (IQR) & $66(55-72)$ & $64(54-72)$ & $65(54.72)$ \\
\hline \multicolumn{4}{|l|}{ Marital status } \\
\hline Single & $9(3.6)$ & $31(1.7)$ & $40(2.0)$ \\
\hline Married & $215(86.0)$ & $1745(97.5)$ & $1960(96.1)$ \\
\hline Other & $26(10.4)$ & $14(0.8)$ & $40(2.0)$ \\
\hline \multicolumn{4}{|l|}{ Year of diagnosis } \\
\hline 2005 & $31(11.9)$ & $148(7.9)$ & $179(8.4)$ \\
\hline 2006 & $18(6.9)$ & $177(9.4)$ & $195(9.1)$ \\
\hline 2007 & $26(10.0)$ & $157(8.4)$ & $183(8.6)$ \\
\hline 2008 & $27(10.3)$ & $171(9.1)$ & $198(9.3)$ \\
\hline 2009 & $22(8.4)$ & $185(9.9)$ & $207(9.7)$ \\
\hline 2010 & $25(9.6)$ & $196(10.4)$ & $221(10.3)$ \\
\hline 2011 & $29(11.1)$ & $171(9.1)$ & $200(9.4)$ \\
\hline 2012 & $30(11.5)$ & $216(11.5)$ & $246(11.5)$ \\
\hline 2013 & $17(6.5)$ & $213(11.3)$ & $230(10.8)$ \\
\hline 2014 & $36(13.8)$ & $244(13.0)$ & $280(13.1)$ \\
\hline \multicolumn{4}{|l|}{ Status } \\
\hline Alive & $172(65.9)$ & $1162(61.9)$ & $1334(62.4)$ \\
\hline Dead & $83(31.8)$ & $675(35.9)$ & $758(35.4)$ \\
\hline Unknown & $6(2.3)$ & $41(2.2)$ & $47(2.2)$ \\
\hline \multicolumn{4}{|l|}{ Summary stage } \\
\hline In situ & $19(7.3)$ & $136(7.2)$ & $155(7.2)$ \\
\hline Localized & $148(56.7)$ & $1086(57.8)$ & $1234(57.7)$ \\
\hline Regional & $21(8.0)$ & $144(7.7)$ & $165(7.7)$ \\
\hline Distant metastasis & $25(9.6)$ & $134(7.1)$ & $159(7.4)$ \\
\hline Unknown & $48(18.4)$ & $378(20.1)$ & $426(19.9)$ \\
\hline \multicolumn{4}{|l|}{ Grade } \\
\hline Well differentiated & $56(21.5)$ & $418(22.3)$ & $474(22.2)$ \\
\hline Moderately differentiated & $37(14.2)$ & 209 (11.1) & $246(11.5)$ \\
\hline Poorly differentiated & $80(30.7)$ & $722(38.4)$ & $802(37.5)$ \\
\hline Undifferentiated & $3(1.1)$ & $30(1.6)$ & $33(1.5)$ \\
\hline Unknown & $85(32.6)$ & $499(26.6)$ & $584(27.3)$ \\
\hline
\end{tabular}

$S D=$ standard deviation; $I Q R=$ interqiuartile range.

significant (Figure $2 \mathrm{C}$ ). Among males, however, the decrease in survival probability with age was statistically significant (Figure 2D).

\section{Survival by grade and stage of tumour}

Figure $3 \mathrm{~A}$ shows the differences in survival probability between the different tumour grades. Patients with well-differentiated tumours had the highest survival probability compared with patients with other grades. Patients with poorly differentiated tumours had the lowest survival probability even when compared with undifferentiated tumours. The P-values shown in figure are derived from the Cox proportional hazard regression for differences in survival probability among different grades. 


\begin{tabular}{|c|c|c|c|c|c|c|c|}
\hline $\begin{array}{l}\text { Interval } \\
\text { (year) }\end{array}$ & $\begin{array}{l}\text { No. at } \\
\text { beginning of } \\
\text { interval }\end{array}$ & $\begin{array}{c}\text { No. } \\
\text { withdrawn } \\
\text { during } \\
\text { interval }\end{array}$ & $\begin{array}{l}\text { Adjusted no. } \\
\text { at risk }\end{array}$ & No. of deaths & $\begin{array}{l}\text { Proportion } \\
\text { surviving the } \\
\text { interval (\%) }\end{array}$ & $\begin{array}{c}\text { Cumulative } \\
\text { survival } \\
\text { proportion } \\
(\%)\end{array}$ & $\begin{array}{c}\text { Standard } \\
\text { error of } \\
\text { cumulative } \\
\text { survival }\end{array}$ \\
\hline 0 & 2083 & 8 & 2079.0 & 314 & 85 & 85 & 0.01 \\
\hline 1 & 1761 & 3 & 1759.5 & 139 & 92 & 78 & 0.01 \\
\hline 2 & 1619 & 41 & 1598.5 & 98 & 94 & 73 & 0.01 \\
\hline 3 & 1480 & 171 & 1394.5 & 54 & 96 & 71 & 0.01 \\
\hline 4 & 1255 & 157 & 1176.5 & 31 & 97 & 69 & 0.01 \\
\hline 5 & 1067 & 154 & 990.0 & 31 & 97 & 67 & 0.01 \\
\hline 6 & 882 & 141 & 811.5 & 25 & 97 & 64 & 0.01 \\
\hline 7 & 716 & 131 & 650.5 & 22 & 97 & 62 & 0.01 \\
\hline 8 & 563 & 113 & 506.5 & 17 & 97 & 60 & 0.01 \\
\hline 9 & 433 & 110 & 378.0 & 9 & 98 & 59 & 0.01 \\
\hline 10 & 314 & 115 & 256.5 & 4 & 98 & 58 & 0.01 \\
\hline 11 & 195 & 97 & 146.5 & 5 & 97 & 56 & 0.02 \\
\hline 12 & 93 & 92 & 47.0 & 1 & 98 & 55 & 0.02 \\
\hline
\end{tabular}

Figure $3 \mathrm{~B}$ shows the survival probability for the different stages of cancer at diagnosis. The earlier the stage of cancer at diagnosis, the higher the survival probability. While $97 \%$ of patients with in-situ tumours survived the first year after diagnosis, only $56 \%$ of patients with distant metastatic tumours survived the first year. The $P$-values shown in figure are derived from
Cox proportional hazard regression for differences in survival probability among different stages.

\section{Discussion}

The present study is the first in Jordan that aimed to assess the survival probability of bladder cancer in the Jordanian population at the national level. The findings

\section{Figure 1 Overall survival curve with confidence intervals for bladder cancer, Jordan 2018}

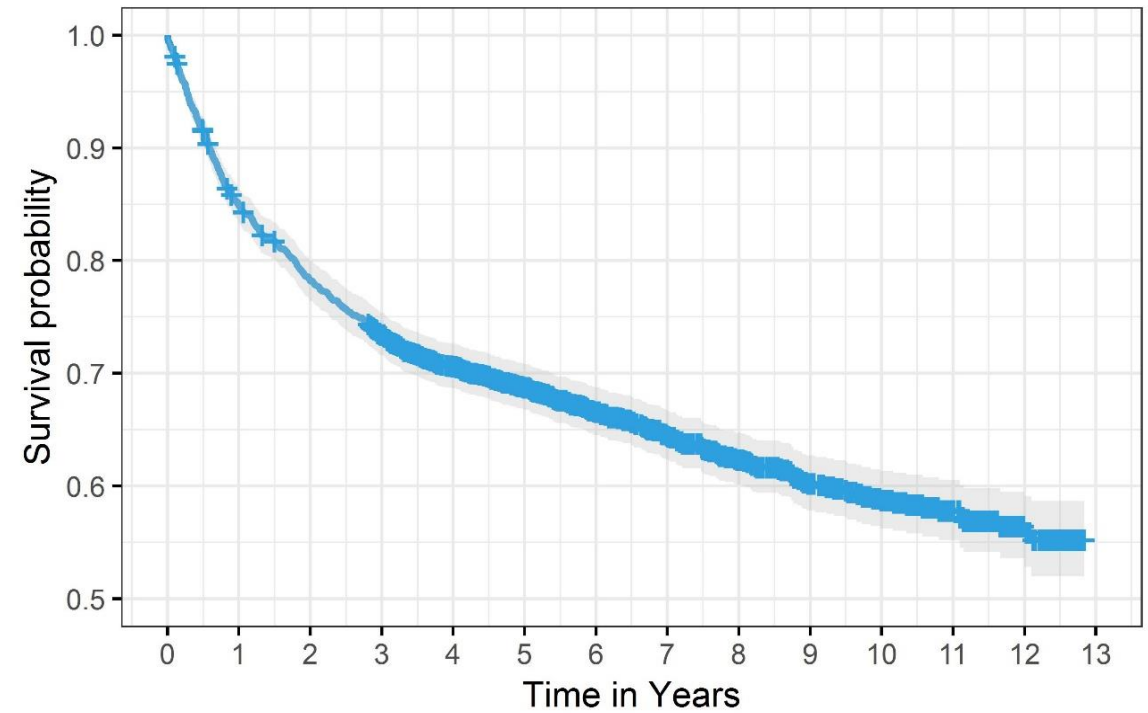

Number at risk

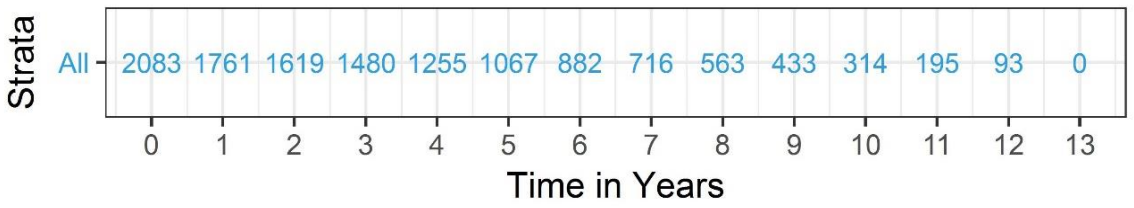


Figure 2 Survival probabilities for patients with urinary bladder cancer diagnosed during 2005-2014, Jordan, 2018, by sex (A), age (B), age in females (C), age in males (D)
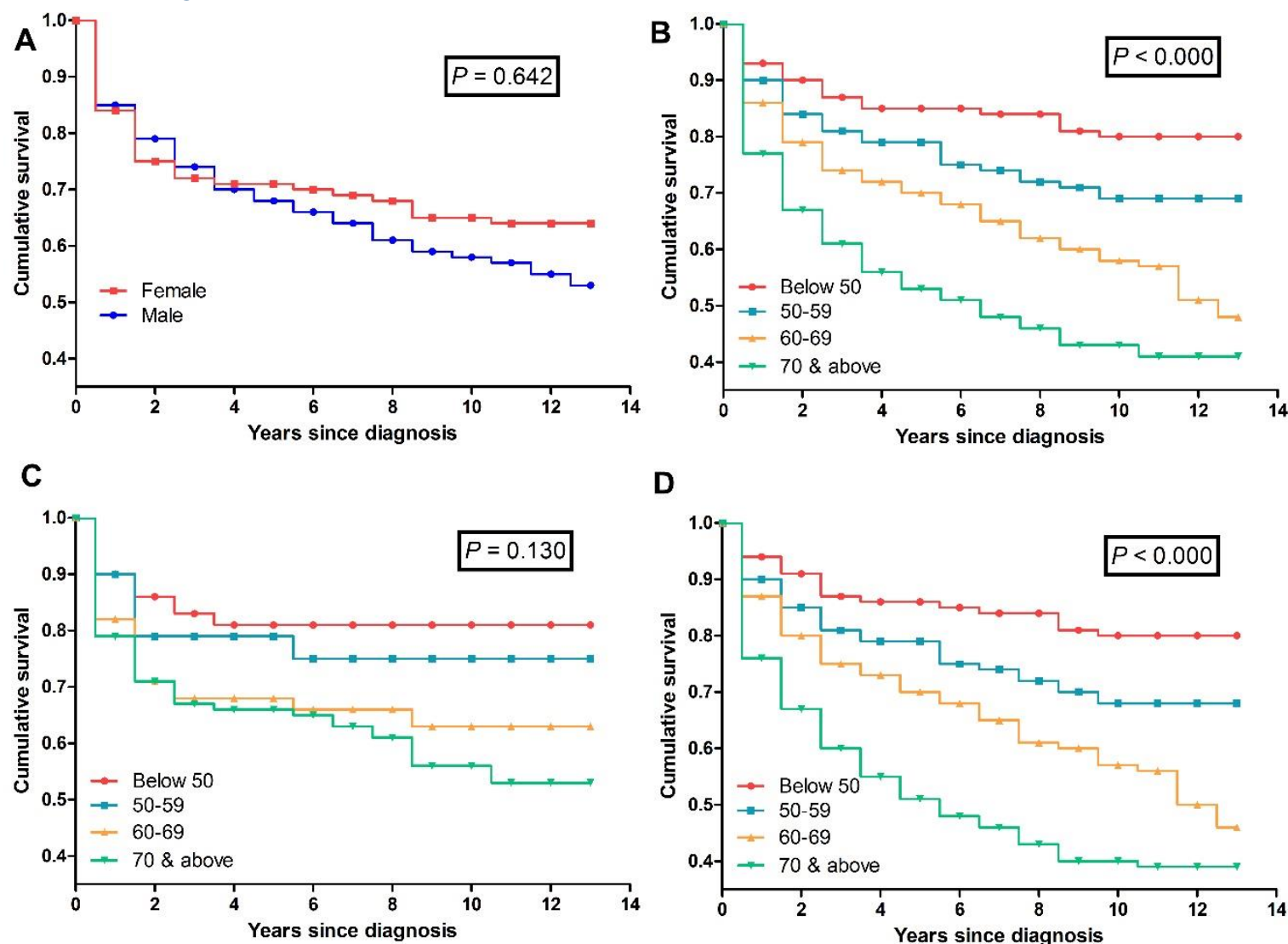

D

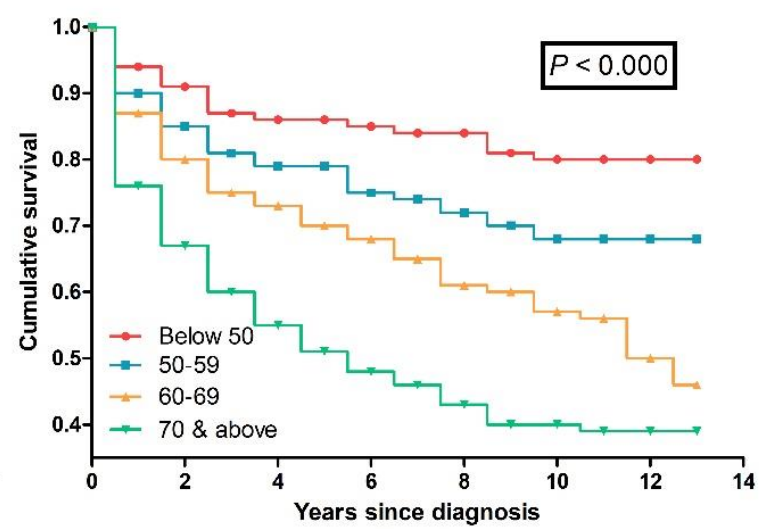

can be considered a national record because they are based on a large population and an almost consistent reporting method. All urinary bladder cancer cases in Jordanians registered in the Jordan cancer registry during 2005-2010 were included in the study. We also aimed to identify groups of the population at higher risk of lower survival.

In the USA, the 5-year survival for urinary bladder cancer was $76.8 \%$ for patients diagnosed in the period 2008-2014 (7). According to the International Agency for Research on Cancer, the 5-year survival for urinary

bladder cancer exceeded 70\% in China, Singapore and the Republic of Korea compared with less than 50\% survival in other countries in Asia (12). In a survival analysis study in the Islamic Republic of Iran, the 5-year survival rate was $57.5 \%$ in 514 patients who were diagnosed with urinary bladder cancer between 2001 and 2009 (11). Our study showed that the overall 5-year survival rate for patients with urinary bladder cancer in Jordan was $69 \%$. This comparison shows that patients with urinary bladder cancer in Jordan have relatively high survival compared with other countries in Asia and comparable

Figure 3 Survival probabilities for patients with urinary bladder cancer diagnosed during 2005-2014, Jordan, 2018, by summary grade (A) and stage (B)
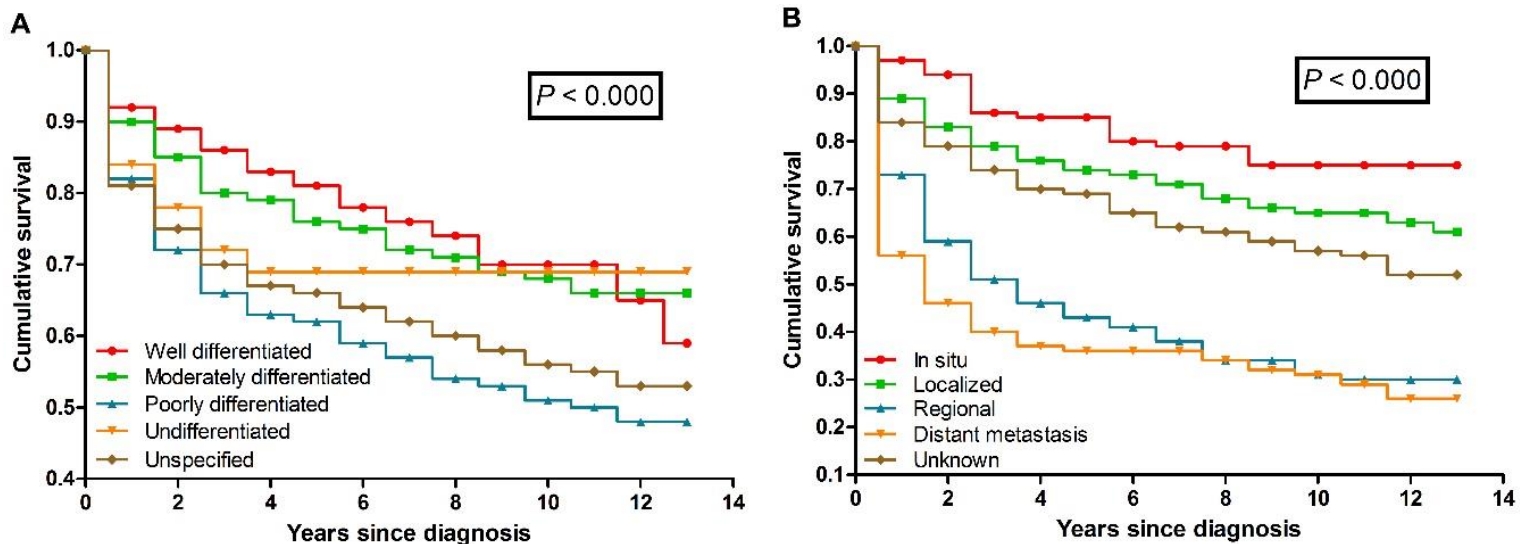
survival to that reported in the developed countries. The better survival in Jordan might be explained by the more advanced cancer care in Jordan compared with some neighbouring countries (13). However, the cancer grade of $27.3 \%$ of the patients in our study was unknown. If the unknown cases were better classified, it might result in a higher percentage with favourable grade and stage and hence better survival rates among our patients. Better pathological classification might shed a light on the unknown grades.

Bladder cancer was more common in males than females. According to the American Society of Clinical Oncology, men were four times more likely than women to be diagnosed with bladder cancer (14). This cancer is the fourth most common cancer in men in the USA and the eighth in the United Kingdom of Great Britain and Northern Ireland (15,16). In 2014, bladder cancer in Jordan ranked third of the top 10 cancers in men (4). Our study supports this ranking as most $(87.8 \%)$ bladder cancer patients were men. Several studies have investigated differences in survival of bladder cancer by sex $(17,18)$. In Norway, a study that included 15129 patients diagnosed with bladder cancer between 1997 and 2011 found that men had a better prognosis than women. The 2-, 5- and 10-year relative survival rates were, respectively, $84.0 \%$, $75.1 \%$, and $66.3 \%$ for men and $79.6 \%, 71.7 \%$, and $64.5 \%$ for women (17). A population-based cohort study that included 36344 patients with urinary bladder cancer diagnosed between 1997 and 2014 found that women had slightly higher mortality than men. This higher mortality in women was limited to those diagnosed with muscleinvasive tumours (18). In another population-based study in Canada, the 5-year cancer-specific survival and overall survival of the full cohort of 5259 patients did not differ between women and men (19). However, our study did not find any significant difference in survival between males and females. The 5-year survival rates were $68 \%$ and $71 \%$ in males and females, respectively. This lack of difference in survival might be due to the similarity in tumour properties such as stage and grade between males and females.

Survival rates for bladder cancer are generally higher in younger patients and decrease with increasing age. Therefore, age is widely accepted as a strong and independent risk factor for developing bladder cancer. In the USA, the overall 5-year survival decreased significantly from $90.8 \%$ in patients younger than 50 years to $81.3 \%$ in patients older 50 years (9). In England, the 5 -year net survival for men with bladder cancer ranged from $73 \%$ in patients younger than 50 years to $43 \%$ in patients older than 80 years during 2009-2013 (16). As expected, our study showed the same pattern as the overall survival decreased significantly as the age of the patients increased. The overall 5-year survival dropped from $85 \%$ in patients younger than 50 years to $53 \%$ in patients older than 70 years. Even after categorizing our study population into only two age groups (younger and older than 50 years), survival differed significantly between the two groups.
Different clinical and pathological prognostic factors have been proposed for survival of bladder cancer, including tumour stage, differentiation of tumour, and surgical and distant metastasis. A high proportion $(80 \%)$ of bladder cancer cases in Jordan have a known stage recorded at diagnosis. Most patients (57.7\%) in our study were diagnosed at stage I (localized tumour) and only 7\% were diagnosed with distant metastatic tumours. In the USA about half of bladder cancer patients are diagnosed at stage I (15). Poorly differentiated tumours were the most common grade among our patients representing $37.5 \%$ of the cases. Our analysis showed that grade and stage were significant predictors of survival of bladder cancer. The probability of dying was significantly higher for those with poorly differentiated tumours compared with those with well differentiated tumours. Survival probability was much higher for patients diagnosed at early cancer stages, such as in-situ and localized tumours compared with those with regional and metastatic tumours. The 5-year survival probability dropped from $85 \%$ for the in-situ tumours to $36 \%$ for metastatic tumours. Previous studies have shown that bladder cancer survival is highly dependent on stage at diagnosis. The 5-year survival probability varied from $92.4 \%$ for localized stage cancers to $25.4 \%$ for distant metastatic cancer (9). Highly and moderately differentiated tumours had a survival probability of $93.5 \%$, while poorly differentiated tumours had a survival probability of $65.8 \%$ (9).

Our study has some limitations. We only analysed data available at the Jordan cancer registry. This database lacks information about some risk factors (e.g. dietary factors and occupational exposure to carcinogens). Therefore, we were unable to investigate the effect of these factors. In addition, a high percentage of data was missing, and the reporting of some variables was inconsistent, such as bladder cancer type, smoking status and treatment, so it was not possible to examine the effect of those variables on the survival probability of our patients. In performing our analysis, we assumed that bladder cancer was the cause of death. However, there might be another underlying cause of death since the cancer registry does not have access to data on the specific cause of death. Therefore, our survival probability might be underestimated as deaths from other causes were included in the analysis.

Regular training for focal points at the hospitals about complete documentation and reporting is needed to improve the quality of cancer data. More attention should be paid to cancer survival, since cancer is the second most common cause of death in Jordan. For instance, a new systematic method is needed to improve patient follow-up. An annually updated database on the incidence, prevalence, mortality and survival of all cancers in Jordan needs to be developed. This database can be a trusted source of information to assess cancer treatment programmes and monitor progress of our national cancer control programme.

Funding: None.

Competing interests: None declared. 


\section{Survie des patients atteints de cancer de la vessie, Jordanie, 2005-2014 \\ Résumé}

Contexte : Le cancer de la vessie est le quatrième cancer le plus fréquent en Jordanie. Aucune recherche sur la survie au cancer de la vessie au niveau national n'a été menée auparavant.

Objectifs : La présente étude visait à estimer la probabilité de survie des patients atteints de cancer de la vessie en Jordanie et à identifier les facteurs associés à la survie.

Méthodes : Les données ont été obtenues à partir de la base de données du registre jordanien du cancer. Tous les cas de cancer de la vessie enregistrés en Jordanie entre 2005 et 2014 ont été inclus dans l'étude $(n=2139)$. Les données collectées pour chaque cas incluaient l'âge, le sexe, la date du diagnostic, le stade et le degré du diagnostic. On a recouru à une analyse actuarielle de la survie avec des tables de survie pour déterminer les probabilités de survie globale. La régression de Cox à risques proportionnels a été utilisée pour identifier des facteurs indépendants associés à la survie.

Résultats : Les probabilités globales de survie à 1, 3, 5 et 10 ans pour le cancer de la vessie étaient respectivement de $85 \%, 73 \%, 69 \%$ et $59 \%$ (erreur type = 0,01 respectivement). Aucune différence significative dans les probabilités de survie n'a été observée entre les hommes et les femmes $(p=0,642)$. Les probabilités de survie globale diminuaient significativement avec l'augmentation de l'âge au moment du diagnostic $(p<0,005)$. Une meilleure survie a été observée chez les patients présentant un stade précoce et des tumeurs bien différenciées au moment du diagnostic.

Conclusions : La survie des patients atteints de cancer de la vessie en Jordanie est comparable à celle rapportée dans les pays à revenu élevé. Il manquait un pourcentage élevé de données et la notification de certaines variables était incohérente. Pour améliorer la qualité des données sur le cancer, les points focaux hospitaliers doivent recevoir une formation régulière sur l'enregistrement des données complètes.

$$
\begin{aligned}
& \text { نجاة المرضى المصابين بسرطان المثانة البولية، الأردن، 200 2014 }
\end{aligned}
$$

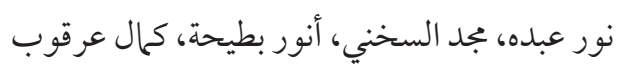

$$
\begin{aligned}
& \text { الخلاصة }
\end{aligned}
$$

الخلفية: يأتي سرطان المثانة البولية في المرتبة الرابعة بين أكثر أنواع السرطان شيوعًا في الأردن. ولمُ تُجرَ أي بحوث من قبل حول النجاة من سرطان المثانة على المستوى الوطني.

الأهداف: هدفت هذه الدر اسة إلى تقدير احتمالية النجاة لدى المرضى المصابين بسر طان المثانة في الأردن، وتحديد العوامل المرتبطة بالنجاة.

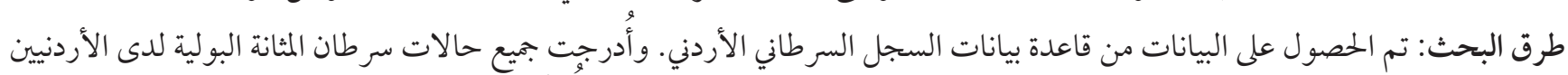

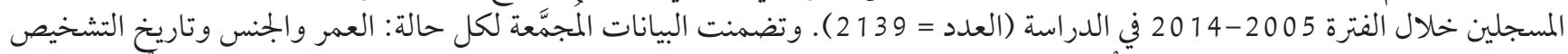

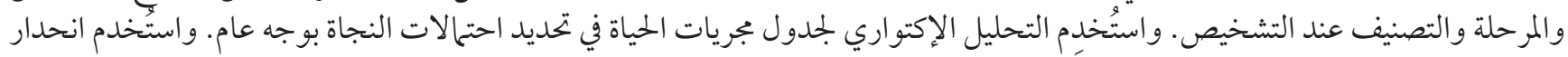

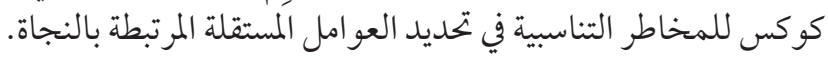

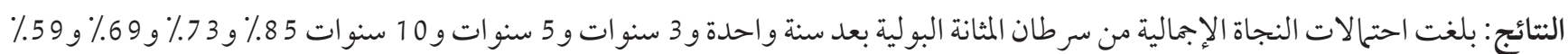

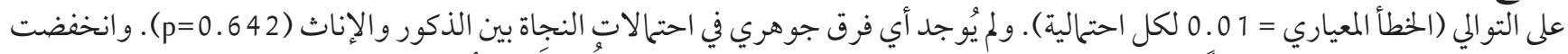

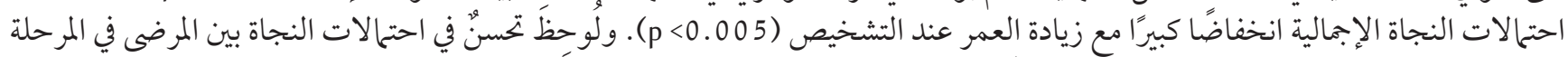

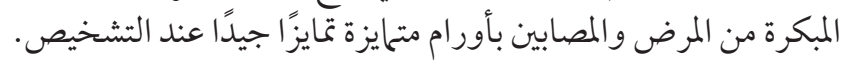

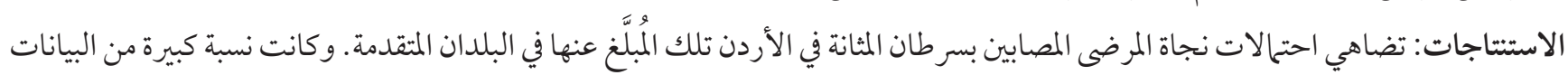

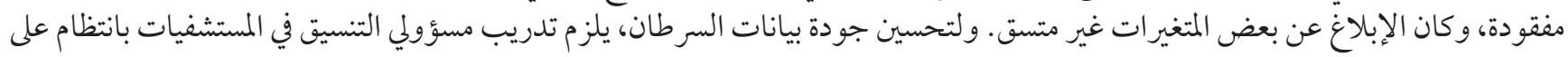
تسجيل البيانات كاملة.

\section{References}

1. $\quad \mathrm{PDQ}^{\oplus}$ Adult Treatment Editorial Board. PDQ bladder cancer treatment. Bethesda, MD: National Cancer Institute; 2018 (https:// www.cancer.gov/types/bladder/hp/bladder-treatment-pdq, accessed 23 August 2020).

2. Epidemiology and risk factors of urothelial (transitional cell) carcinoma of the bladder. Waltham, MA: UpToDate; 2020 (https:// www.uptodate.com/contents/epidemiology-and-risk-factors-of-urothelial-transitional-cell-carcinoma-of-the-bladder, accessed 23 August 2020).

3. The Global Cancer Observatory. Jordan. Lyon: International Agency for Research on Cancer; 2020 (https://gco.iarc.fr/today/data/ factsheets/populations/400-jordan-fact-sheets.pdf, accessed 23 August 2020). 
4. Statistic summary. Jordan Cancer Registry. Cancer incidence in Jordan - 2013. Amman: Noncommunicable Diseases Directorate, Ministry of Health; 2013.

5. Torre LA, Bray F, Siegel RL, Ferlay J, Lortet-Tieulent J, Jemal A. Global cancer statistics, 2012. CA Cancer J Clin. 2015;65(2):87-108. https://doi.org/10.3322/caac.21262

6. Bladder cancer statistics. Bladder cancer is the tenth most common cancer worldwide. London: World Cancer Research Fund; 2018 (https://www.wcrf.org/dietandcancer/cancer-trends/bladder-cancer-statistics, accessed 23 August 2020).

7. Cancer stat facts: bladder cancer. Bethesda, MD: National Cancer Institute; 2017 (https://seer.cancer.gov/statfacts/html/urinb. html, accessed 23 August 2020).

8. Survival rates for bladder cancer. Atlanta, GA: American Cancer Society; 2018 (https://www.cancer.org/cancer/bladder-cancer/ detection-diagnosis-staging/survival-rates.html, accessed 23 August 2020).

9. Feng H, Zhang W, Li J, Lu X. Different patterns in the prognostic value of age for bladder cancer-specific survival depending on tumor stages. Am J Cancer Res. 2015;5(6):2090-27.

10. Jahnson S, Hosseini Aliabad A, Holmäng S, Jancke G, Liedberg F, Ljungberg B, et al. Swedish National Registry of Urinary Bladder Cancer: no difference in relative survival over time despite more aggressive treatment. Scand J Urol. 2016;50(1):14-20. https:// doi.org/10.3109/21681805.2015.1085089

11. Rezaianzadeh A, Mohammadbeigi A, Mobaleghi J, Mohammadsalehi N. Survival analysis of patients with bladder cancer, life table approach. J Midlife Health. 2012;3(2):88-92. https://doi.org/10.4103/0976-7800.104468

12. Sankaranarayanan R, Swaminathan R, Lucas E. Cancer survival in Africa, Asia, the Caribbean and Central America (SurvCan). IARC Scientific Publications volume 162. Lyon: International Agency for Research on Cancer; 2011 (https://survcan.iarc.fr/, accessed 23 August 2020).

13. Abdel-Razeq H, Attiga F, Mansour A. Cancer care in Jordan. Hematol Oncol Stem Cell Ther. 2015;8(2):64-70. https://doi. org/10.1016/j.hemonc.2015.02.001

14. Cancer.Net. Bladder cancer: statistics. Alexandria, VA: American Society of Clinical Oncology; 2021 (https://www.cancer.net/ cancer-types/bladder-cancer/statistics, accessed 17 February 2021).

15. Key statistics for bladder cancer. Atlanta, GA: American Cancer Society; 2018 (https://www.cancer.org/cancer/bladder-cancer/ about/key-statistics.html, accessed 23 August 2020).

16. Bladder cancer statistics. London: Cancer Research UK; 2014 (https://www.cancerresearchuk.org/health-professional/cancer-statistics/statistics-by-cancer-type/bladder-cancer, accessed 23 August 2020).

17. Andreassen BK, Grimsrud TK, Haug ES. Bladder cancer survival: women better off in the long run. Eur J Cancer. 2018;95:52-8. https://doi.org/10.1016/j.ejca.2018.03.001

18. Radkiewicz C, Edgren G, Johansson ALV, Jahnson S, Häggström C, Akre O, et al. Sex differences in urothelial bladder cancer survival. Clin Genitourin Cancer. 2020;18(1):26-34.e6. https://doi.org/10.1016/j.clgc.2019.10.020

19. Patafio FM, Siemens DR, Wei X, Booth CM. Is there a gender effect in bladder cancer? A population-based study of practice and outcomes. J Can Urol Assoc. 2015;9(7-8):269-74. https://doi.org/10.5489/cuaj.2927 